\title{
Da arte invisível ao enraizamento: uma experiência de educação não formal no subúrbio ferroviário de Salvador
}

\author{
Roberta Vasconcelos Leite' (D) \\ Miguel Mahfoud' (D)
}

\section{RESUMO}

Investigamos a proposta educativa do Acervo da Laje, iniciativa de educação não formal localizada no subúrbio ferroviário de Salvador, Bahia. Pela ótica da psicologia da cultura, realizamos entrevista semiestruturada com seu fundador, analisada fenomenologicamente. Identificamos como a vivência pessoal de encontro com a arte mobilizou o reconhecimento de que todos os seres humanos são ontologicamente abertos ao excedente. Com essa premissa, o Acervo da Laje quer superar processos que tornam invisíveis as produções da periferia. Promover a arte local revela-se esforço de restituição para que o excedente humano gerado no subúrbio, mas a ele negado, a ele retorne. No diálogo com Weil, compreendemos que essa proposta educativa distingue-se pelo enraizamento na existência. Concluímos que, enquanto responde a desafios próprios da educação não formal, o Acervo da Laje revela possibilidade singular de educação pautada na valorização concomitante da cultura local e do que nos une como humanos.

PALAVRAS-CHAVE

educação não formal; projetos culturais; psicologia da cultura; fenomenologia; enraizamento.

Universidade Federal de Minas Gerais, Belo Horizonte, MG, Brasil. 


\title{
FROM INVISIBLE ART TO ROOTS: AN EXPERIENCE OF NON- FORMAL EDUCATION IN THE RAILWAY SUBURB OF SALVADOR
}

\begin{abstract}
We investigated the educational proposal of Acervo da Laje, a non-formal education initiative located in the railway suburb of Salvador, Bahia. Under a psychology of culture's perspective, we conducted a semistructured interview with its founder, analyzed phenomenologically. We identify how the personal experience of encountering art mobilized the recognition that all human are ontologically open to surplus. With this premise, the Acervo da Laje wants to overcome processes that make the periphery production invisible. To promote local art reveals an effort of restitution so that the human surplus generated in the suburb, though denied to it, returns to it. In the dialogue with Weil, we understand that this educational proposal is distinguished by its rooting in existence. We conclude that, while responding to the challenges of non-formal education, the Acervo da Laje reveals a singular possibility of education based on the concomitant appreciation of local culture and of what unites us as humans.
\end{abstract}

KEYWORDS

non-formal education; cultural projects; psychology of culture; phenomenology; rooting.

\section{DEL ARTE INVISIBLE A LO ARRAIGO: UNA EXPERIENCIA DE EDUCACIÓN NO FORMAL EN EL SUBURBIO FERROVIARIO DE SALVADOR}

\section{RESUMEN}

Investigamos la propuesta educativa del Acervo de Laje, iniciativa de educación no formal ubicada en el suburbio ferroviario de Salvador, Bahia. Bajo la psicología de la cultura, realizamos entrevista semiestructurada con su fundador, analizada fenomenológicamente. Identificamos cómo la vivencia personal de encuentro con el arte movilizó el reconocimiento de que todos los seres humanos son ontológicamente abiertos al excedente. Con esta premisa, el Acervo da Laje quiere superar procesos que hacen invisibles las producciones de la periferia. Promover el arte local es esfuerzo de restitución para que el excedente humano generado en el suburbio, pero a él negado, regrese. En el diálogo con Weil, comprendemos que esta propuesta educativa se distingue por el arraigo en la existencia. Concluimos que, mientras responde a desafíos propios de la educación no formal, el Acervo da Laje revela posibilidad singular de educación pautada en la valorización concomitante de la cultura local y de lo que nos une como humanos.

educación no formal; proyectos culturales; psicología de la cultura; fenomenologia; arraigo. 


\section{INTRODUÇÃO: A EDUCAÇÃO PARA ALÉM DA ESCOLA}

Enquanto esforço humano de formar as novas gerações, a educação assume o duplo desafio de cuidar do desenvolvimento dos recém-chegados, ao mesmo tempo em que thes apresenta nosso mundo, preparando-os para assumirem a responsabilidade por sua continuidade e transformação (Arendt, 2011). Embora tenha a instituição escolar como seu cenário privilegiado em nossa sociedade, é importante reconhecer que a tarefa educativa é realizada em múltiplos espaços e pelos mais diferentes atores sociais, tanto que desde as décadas de 1960 e 1970 muitos autores têm se oposto à completa identificação entre educação e escolarização, apontando limitações da abordagem formativa da escola em um momento histórico de transição de valores, ideais e horizontes de futuro (Severo, 2015).

Além de não poder responder sozinha pela constituição do sujeito individual e social, a educação escolar no Brasil é palco de desafios e disputas que precedem a fundação da República. Tomada teoricamente como prioridade pela legislação, é recorrentemente relegada a segundo plano pelas instâncias governamentais, de modo que nossa história revela uma lenta e frágil democratização do ensino público, instalando inúmeras dificuldades à construção de uma socialização escolar equitativa (Ramos, 2018). Esse quadro transforma-se substancialmente a partir da redemocratização do país, em fins da década de 1980, podendo-se falar hoje em universalização da escolarização básica, não obstante a exclusão ainda se faça presente de modo alarmante, seja no grande contingente de crianças e adolescentes ainda fora da escola, seja no cotidiano daqueles que, mesmo matriculados, vivenciam a exclusão na escola (Ferraro e Ross, 2017).

Nesse contexto, iniciativas de educação não formal crescem e tomam a cena do associativismo brasileiro no meio popular, criando cenários e paisagens urbanas específicas que merecem cada vez mais espaço como objeto de estudo na área da educação, posto que trazem experiências inovadoras de valorização cultural que muitas vezes conseguem potencializar o desempenho escolar das crianças e jovens envolvidos (Gohn, 2009). De acordo com Sovik (2014), a proposta de tomar a cultura como ferramenta da educação de setores jovens da população pobre tem como marco inaugural no país a fundação do Olodum, em 1979. A partir de então, projetos culturais, de arte-educação ou socioeducativos com iniciativas semelhantes multiplicam-se nos cenários urbanos, configurando-se como tentativas de transformação social por meio da inserção cultural. Especialmente a partir dos anos de 1990, como resposta à violência policial contra a população pobre, esses projetos ganham força: "das cinzas da violência e da negação dos direitos, surge, então, a fênix da cultura" (Sovik, 2014, p. 174).

Nessas inciativas, estimular a produção e a fruição artística configura-se como metodologia privilegiada que a um só tempo favorece o envolvimento do público infantojuvenil e consolida propostas de formação sobre direitos humanos, cidadania, identidade comunitária e posicionamento crítico às desigualdades e exclusões sociais (Gohn, 2007; Villaça, 2014). Além de fomentar o desenvolvimento de crianças e jovens em situação de vulnerabilidade, a criação de espaços culturais na periferia tem sido reconhecida como alternativa que promove fortalecimento comunitário 
e resgate da história local, instituindo novas formas de apropriação do território e fortalecimento da memória coletiva (Von Simson, Park e Fernandes, 2007).

Não obstante reconheçam a importância de que a população marginaliza$\mathrm{da}$ alcance autorrepresentação positiva para que possa se tornar protagonista da transformação das relações sociais, há leituras críticas dessas ações educativas que denunciam o risco do assistencialismo (Matos, 2015). Ao investirem em novas formas de reconhecimento do valor da cultura da população negra da periferia, muitas vezes com grande empenho para visibilização da juventude pobre na mídia, os projetos podem se tornar uma forma própria de ação política que abre mão da mobilização social e do foco na pressão sobre o poder público. O resultado seria uma espécie de falsa inclusão social — já que a formação cultural não garante a superação do desemprego estrutural - somada à precariedade dessas iniciativas, tantas vezes dependentes de financiamentos incertos e do carisma de líderes frequentemente centralizadores.

Mas a suspeição dos projetos não pode ser o único caminho analítico. Se a cena dos projetos culturais é madura, com modelos, formatos e fontes de financiamento, se já se estabeleceu uma tradição de desencadear a força criativa de jovens, se os projetos persistem através de décadas, eles têm um significado social importante. Não só tranquilizam as más consciências e nem todos folclorizam o jovem pobre e negro [...]. Ao contrário, alguns formam pessoas atuantes vindas do mundo popular, trabalhadores das artes e de outros espaços. [...] Esses atores falam da desigualdade social que os motiva a partir de lugares sociais diferentes, mas têm em comum o entusiasmo e a percepção de transformações, de tal maneira que suas vozes são às vezes quase indistinguíveis. Esses casos de sucesso apresentam respostas à pergunta: se temos em comum nossa humanidade, o que podemos fazer em comum? (Sovik, 2014, p. 175)

Assim, mesmo em face dos riscos e desafios que lhe são próprios, os projetos culturais se consolidam como modalidade de educação não formal que tem grande incidência na realidade brasileira. Severo $(2015$, p. 566) sinaliza que sua força pode residir nas "práticas educativas abertas, plurais e contextualizadas, em que a cultura e a experiência vivida pelo sujeito são a base para a construção de saberes e atitudes críticas e criativas".

Investigar os fundamentos e as bases filosóficas das concepções educativas desses projetos com base na perspectiva dos educadores que são seus protagonistas pode configurar-se como contribuição real para a compreensão desse campo ainda carente de investigações científicas e da sistematização das metodologias pedagógicas utilizadas (Gohn, 2009). Dando voz aos educadores que se mostram "decididos a transformar positivamente seu meio e seu mundo" (Gohn, 2007, p. 80), as pesquisas têm reconhecido a centralidade de sua atuação na conformação "de entidades que cada vez mais fogem da pecha de meras instituições assistenciais” (Gohn, 2007, p. 80). A título de exemplo, encontramos em Souza e Ciampa (2017) análises de trajetórias de educadores sociais que atuam em iniciativas de educação não formal. Focalizando como processos identitários podem conjugar 
pensamento utópico e pensamento histórico, esses autores desvelam a importância da reflexividade sobre a própria atuação para que educadores possam amadurecer suas práticas e propostas educativas.

De modo semelhante, pretendemos no presente artigo delinear fatores constitutivos da proposta educativa de uma iniciativa de educação não formal tomando como base a análise da experiência de seu fundador. Trata-se de um espaço cultural nascido no subúrbio ferroviário de Salvador: o Acervo da Laje, que será descrito no tópico a seguir. O olhar que lançamos sobre essa iniciativa parte da psicologia da cultura fenomenológica (Augras, 1995), de modo que nos interessa compreender esse fenômeno educativo pela perspectiva de quem protagoniza sua produção. Aprofundando o modo como o educador elabora sua história de vida e sua experiência à frente do Acervo da Laje, compreendemos que podemos contribuir para desvelar motivações, a visão de ser humano que fundamenta seu trabalho, modos de constituição de vínculos comunitários, bem como possibilidades e desafios dessa modalidade educativa.

\section{O ACERVO DA LAJE: ARTE E CULTURA DO SUBÚRBIO FERROVIÁRIO DE SALVADOR AO ALCANCE DE TODOS}

Defendendo a inseparabilidade entre arte e educação, o Acervo da Laje tem sua origem em uma pesquisa etnográfica sobre artistas invisíveis do subúrbio ferroviário de Salvador, desenvolvida de 2009 a 2012 pelo professor José Eduardo Ferreira Santos em parceria com o fotógrafo Marco Iluminati. Tendo adquirido obras dos artistas pesquisados, José Eduardo constituiu um acervo que em pouco tempo deixou de ser apenas seu: a laje no coração de Novos Alagados, ${ }^{1}$ que até então era sua moradia, transformou-se em espaço aberto a todos, palco de projetos educativos e de uma nova forma de "reconstrução do mosaico simbólico da periferia de Salvador" (Santos, 2014, p. 14) na medida em que busca "trazer de volta a memória e a beleza de um lugar que foi sucessivamente esquecido pelos poderes públicos; fazer com que as pessoas passem a conhecer aquilo que lhes foi negado desde sempre" (Santos, 2014, p. 155).

Reunindo obras de arte adquiridas, doadas e até mesmo encontradas no lixo, além de artefatos históricos e naturais (como conchas), o espaço logo ficou pequeno e, em 2015, foi inaugurada a Casa 2, especialmente construída para ser uma extensão do Acervo da Laje e abrigar novas obras, sendo também destinada à realização de oficinas, reuniões e palestras. Além das constantes visitas de escolas e centros educativos da região, entre as várias atividades educativas desenvolvidas no Acervo da Laje, destacamos como exemplos as oficinas de fotografia realizadas em

1 Hoje urbanizada, essa região é conhecida historicamente como paisagem em que, durante décadas, a comunidade construiu suas palafitas sobre o mangue. Em seu livro Novos Alagados: histórias do povo e do lugar (Santos, 2005), José Eduardo discorre sobre o processo dessa constituição da comunidade, indicando como as palafitas, para além de documentarem precariedade, denotam a criatividade popular em condições adversas. 
2013 com a pesquisadora Marcela Hausen. Nessas oficinas, adolescentes da região foram convidados a desenvolver sua própria capacidade de criação do belo por meio de um mergulho na beleza natural que os cercava e na pujança cultural e histórica do lugar, que quase sempre passam despercebidas. Outra iniciativa que chama atenção por seu caráter inovador é o projeto Ocupa Lajes: de fevereiro a junho de 2016 foram realizadas oficinas de artes visuais, intervenções e exposições no Acervo e em diversos outros pontos do subúrbio de Salvador. Com nova edição prevista para 2018, esse projeto parte da compreensão de que a laje é espaço representativo da periferia, lócus experimental de socialização que merece ser celebrado e, como o Acervo, transformado em espaço cultural. ${ }^{2}$

Alcançando expressivo reconhecimento em âmbito local e nacional, ${ }^{3}$ essa iniciativa recebe doações, especialmente de artistas, e eventualmente financiamento de órgãos públicos ou privados para alguns dos projetos empreendidos, mas se desenvolve prioritariamente com recursos próprios e com o trabalho de José Eduardo e de sua esposa, Vilma. Nos tempos de apologia ao esquecimento em que vivemos, a experiência do Acervo da Laje nos interessa particularmente pela valorização de produções artísticas locais em um movimento de restituição da memória local, que tanto mira a formação dos jovens quanto o fortalecimento da comunidade em que se insere. Além disso, destacamos o caráter peculiar da trajetória de vida de José Eduardo: nascido em Novos Alagados, graduou-se em pedagogia, foi educador e coordenador em projetos sociais da região, formou-se pesquisador no mestrado em psicologia, doutorado em saúde pública e pós-doutorados em psicologia e em estudos culturais. $\mathrm{O}$ reconhecimento de que o curso de sua vida poderia ter tomado tantas outras direções é mais um fator que nos instiga a aprofundar o modo como ele elabora sua experiência e os fundamentos da proposta educativa que hoje ocupa o centro de sua atividade profissional.

\section{DE ONDE PARTIMOS}

Como dito, esta pesquisa foi desenvolvida no campo da psicologia da cultura de orientação fenomenológica (Augras, 1995; Mahfoud, 2003), a qual se empenha por acolher a convocação de Husserl (2006) à reconstrução do fazer científico com base nos aportes da fenomenologia.

2 Para maiores informações, confira a página do Acervo da Laje no Facebook: <www. facebook.com/acervodalaje $>$.

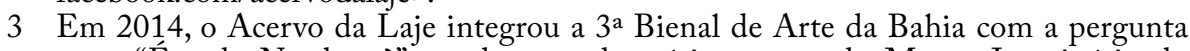
tema "É tudo Nordeste?", sendo uma das várias seções do Museu Imaginário do Nordeste (Bienal da Bahia, 2014). Recebeu público estimado em cerca de mil pessoas nos cem dias do evento. No mesmo ano, José Eduardo e sua esposa, Vilma, integraram a mesa-redonda Agentes culturais do Brasil que usam a arte como ferramenta para a mudança social no Simpósio Usos da Arte, evento integrante da $31^{\mathrm{a}}$ Bienal de Arte de São Paulo (Bienal de São Paulo, 2014). Cabe destacar ainda a ampla divulgação do Acervo da Laje em matérias veiculadas na TV (Nordeste Mais, 2017) e a palestra recentemente proferida para o TEDx: Como transformar sua casa em uma obra de arte? (Santos, 2017). 
Campo consolidado no país por Monique Augras, em meados da década de 1970, a psicologia da cultura nasceu da aspiração por um saber respeitador da diversidade cultural brasileira que superasse o etnocentrismo e o empirismo das abordagens então vigentes. Ocupando-se de objetos próximos aos da antropologia cultural, sua especificidade está em focalizar a constituição humana por meio da análise dos fenômenos culturais. Para tanto, empenha-se em "descrever as modalidades pelas quais se constrói e se expressa a pessoa dentro de determinada cultura e, a partir dessa observação, tentar compreender aspectos fundamentais da realidade humana" (Augras, 1995, p. 19).

Um dos caminhos privilegiados de investigação nessa vertente é a análise das elaborações dos sujeitos da experiência. Reconhecemos aí uma via de acesso privilegiado à unidade mutuamente constitutiva entre sujeito e mundo, já que ao elaborar o que vive a pessoa reconstrói a própria experiência, expressando sua pessoalidade em constante diálogo com os problemas e tensões próprios de sua realidade social. Ancorando-se no reconhecimento da intencionalidade característica do fluxo de vivências (Husserl, 2006), essa modalidade de investigação reconhece que por meio da análise das vivências é possível descrever tanto as características estruturais do sujeito que se coloca no mundo quanto do mundo-da-vida que se manifesta a ele (Ales Bello, 2004; Zilles, 2007).

Para apreender a unidade sujeito-mundo que o fenômeno expressa, a fenomenologia propõe a adoção de uma atitude metodológica que dê conta de descrevê-lo e compreendê-lo em suas características essenciais, buscando também conservar sua complexidade e vitalidade. Como premissa do processo de investigação, a atitude fenomenológica pressupõe então a realização da epoché com vistas a superar o subjetivismo e a descrição objetivante da estrutura e das práticas sociais ao tomar a experiência privilegiando a unidade originária entre consciência e mundo (Ales Bello, 1998).

A epoché constitui-se como procedimento de suspensão de juízos que se referem tanto ao objeto que se pretende conhecer quanto às condições de possibilidade do conhecimento. O objetivo é evitar ao máximo a imposição de categorias próprias àquilo que se manifesta a nós. Isso implica um chamado a reconhecer como a posição existencial do investigador pode modular sua atuação, sendo importante examiná-la quando se empreendem pesquisas fenomenológicas, ${ }^{4}$ de modo que se possa evitar o risco de naturalização dos procedimentos adotados (Barreira, 2011).

Nesse sentido, reconhecemos a importância de explicitar o ponto do qual partimos ao iniciar a presente investigação. A escolha por investigar a experiência do Acervo da Laje pela perspectiva de seu fundador é pautada em nossa sensibilidade

4 Peres (2014) pontua que a epoché acompanha o tipo de investigação fenomenológica que se ocupa da subjetividade transcendental, não sendo, portanto, uma exigência nas investigações da psicologia que se ocupam de ontologias regionais, isto é, que buscam delimitar características essenciais de certos fenômenos. Entretanto, entendemos que a epoché, com sua proposta crítica e construtiva de dar as razões do que examinamos, é fundamental a nosso empenho de colher o fenômeno em sua estrutura essencial (Leite e Mahfoud, 2010). 
a esse tipo de iniciativa, que tomamos como particularmente rica e provocadora. Valorizar a elaboração pessoal como elemento dinamizador da constituição dos processos educativos e culturais é uma marca de nossa trajetória pessoal e acadêmica, sendo, portanto, um viés que nos acompanha.

Entendemos que realizar a epoché dessa perspectiva significa colocá-la diante dos olhos e tomá-la de modo crítico, acolhendo o chamado a continuamente nos recolocarmos e nos dispormos ao diálogo com quem formula outras perguntas aos mesmos fenômenos. Nesse movimento, reconhecemos que outras visadas podem ser complementares às compreensões que alcançamos, ressaltando mesmo a fundamental importância de que abordagens diferentes possam se articular e, quando necessário, corrigirem umas às outras na construção coletiva do conhecimento. Assim, compreendemos que o chamado à suspensão de juízos não significa uma tentativa ingênua de esquecimento de nossos pontos de partida, mas sim uma contínua problematização do nosso olhar.

\section{COMO CAMINHAMOS}

A escolha da experiência educativa do Acervo da Laje como objeto de nossa análise se deu a partir de investigação anterior empreendida com quatro guardiões de memórias contemporâneos, pessoas que, não sendo membros de comunidades tradicionais e cuja formação profissional a princípio não implicaria a dedicação a atividades dessa natureza, tornaram-se protagonistas na preservação cultural de algo que tomam do passado. O educador José Eduardo integrou essa pesquisa em que buscamos desvelar como se configura a relação entre experiência ontológica e tradição na elaboração da investigação dos guardiões de memórias (Leite, 2015).

Os dados foram coletados em entrevista semiestruturada de orientação fenomenológica, inteiramente gravada em áudio e realizada no Acervo da Laje. Dada a importância de que não fosse mantido sigilo quanto à identidade do participante, além da assinatura do Termo de Consentimento Livre e Esclarecido, recebemos autorização para manter o nome próprio das pessoas e instituições citadas. Durante a entrevista buscamos favorecer a descrição das vivências (Barreira e Ranieri, 2013), tendo como questão norteadora: "Como você chegou a se envolver neste trabalho de preservação cultural?” Não seguimos roteiro com outras perguntas e, quando necessário, buscamos auxiliá-lo a retomar a descrição do modo como vivencia os temas abordados (Bosi, 2012).

A entrevista audiogravada foi integralmente transcrita e textualizada. Na análise dos dados, seguimos as diretrizes metodológicas para pesquisa fenomenológica formuladas por Van der Leeuw (1964) com vistas a chegar a compreender as vivências e suas conexões de sentido.

A seguir, apresentamos nossa análise da entrevista com José Eduardo acerca da constituição do Acervo da Laje. Considerando os objetivos do presente trabalho, priorizamos as descrições que remetem aos fundamentos de sua proposta educativa, com particular atenção à concepção de ser humano que se delineia em sua narrativa. Para favorecer a dinâmica da leitura e o acesso à experiência, optamos por grafar em itálico todas as expressões retiradas da transcrição, intercalando-as com nossas 
sínteses e compreensões. No tópico posterior e na conclusão, confrontamos nossas análises com marcos teóricos para ampliar e retificar as compreensões alcançadas.

\section{CONHECENDO O ACERVO DA LAJE E SUAS RAIIZES}

Para empreender a análise da experiência, a pergunta se recoloca: "O que é o Acervo da Laje?”. Vejamos como José Eduardo nos responde:

É um espaço montado fruto de pesquisa etnográfica. É uma laje com mais de cinco mil obras encontradas, compradas. Tem desde conchinhas do mar até quadros, altares, tudo. Placas de ônibus, placas de rua, tijolos das antigas olarias. Tudo o que jogam fora, tudo o que diz da história do lugar: tudo está guardado para as pessoas verem como é que é.

Em primeiro lugar, o Acervo nos é apresentado como espaço para as pessoas verem desde objetos de arte até o que jogam fora, desde elementos naturais, como conchinhas do mar, até artefatos históricos, como placas de ruas. Tudo o que José Eduardo reúne está lá, tudo o que diz da história do lugar. Na diversidade de objetos reunidos e dispostos, apreendemos que o Acervo é o espaço em que o excedente está ao alcance da mão:

Porque a arte é sempre uma ruptura, a arte é uma possibilidade do sujeito se dar conta de que é humano, de que nasceu para ter um excedente. Isso mesmo nos espaços onde as pessoas não têm acesso, porque, quando elas encontram, sabem que foram feitas para aquilo.

O excedente, para José Eduardo, é a expressão do dinamismo humano de suplantar barreiras, de precisar deixar uma contribuição, minima que seja, mas sempre diferente, autoral. O Acervo é, portanto, lugar para as pessoas verem e se verem; contemplarem artefatos e poderem se dar conta de que tanto quem os produziu quanto qualquer um de nós nos situamos dentro da bumanidade.

Nesses espaços onde a humanidade é diminuída, onde a vulnerabilidade acontece, onde o risco social é grande e as pessoas são privadas do acesso à arte, há uma necessidade de encontro com essa forma de elaboração simbólica. [...] Então! Quando as pessoas vêm aqui, elas se dão conta de que pobreza não é correlato de falta de criatividade, imaginação, e que pobreza não é privação cultural. Você pode ter uma situação de vida que não seja abastada e pode ter contato com aquilo que foi elaborado culturalmente. $\mathrm{E}$ isso provoca as pessoas.

Enquanto ao subúrbio tantas vezes é dado um espelho quebrado em que as pessoas só vêm cacos de si mesmos, José Eduardo quer apresentar a elas um espelho íntegro. Um espelho em que a comunidade como um todo e cada um em primeira pessoa possa se ver como é, em sua complexidade multifacetada, sem negar os problemas e sem se deixar definir apenas pelo que os diminui enquanto humanos. Espaço de encontro com objetos que documentam formas de elaboração simbólica 
produzidas por quem é dali ou referentes àquele lugar específico, o Acervo reflete o rosto do seu território:

O subúrbio ferroviário de Salvador, que tem seiscentas mil pessoas e é uma área histórica, mas caracterizada pela pobreza, violência. Tanto que eles não conseguem conceituar como lugar que tem educação, tem arte, tem cultura. E, no entanto, é um lugar que tem tudo isso, mas que foi abafado desde o século XVI. É uma contradição das contradições: um lugar que tem artefatos do século XVI e que é preenchido de pobreza, pobreza que não permite que ninguém nem sonhe que exista isso, que exista história, que exista...

Diante desse verdadeiro antirregistro ${ }^{5}$ imposto ao subúrbio, José Eduardo entende que sua obra é de restituição: empenho para que o excedente gerado no subúrbio, mas a ele negado, a ele retorne. Trata-se de um esforço de reconstrução do lugar com os seus próprios elementos: dos cacos estilhaçados se faz um mosaico. Um mosaico que se quer espaço de convergência de toda essa energia que se vê dispersa: lugar físico para fazer a pertença acontecer.

Enquanto tudo diz: "não pertença", o Acervo está dizendo: "pertença!" por meio do cuidado com a memória e da valorização do que o subúrbio tem. Tem a violência, tem o drama, tem a vida, tem a poética, tem a beleza, tem... Tem uma complexidade que José Eduardo quer "re-apresentar" por meio de objetos que têm uma estética própria dispostos de certo jeito, com vistas a promover impacto e fascinio. Assim como toda forma de arte, ${ }^{6}$ o Acervo tem o objetivo claro de ser uma ruptura, instaurar o novo, uma proposta qualitativamente diversa dentro dos horizontes estreitos em que podemos nos encontrar. Trata-se de um lugar que quer provocar as pessoas e formá-las a responder de um modo novo, porque lidando com o simbólico que você não mensura, isso te empodera.

Em suma, escancarando o excedente como constitutivo do humano mesmo nos contextos de privação, o Acervo documenta que todos são gente dando visibilidade à riqueza cultural do subúrbio ferroviário com a materialidade que ela exige. Restituindo ao seu lugar tudo o que reuniu em anos de pesquisa, seu curador promove encontros para celebrar a existência em sua complexidade e desafiar o antirregistro imposto à periferia.

5 Espinheira (1998, p. 23) propõe o termo para melhor definir o esquecimento na história dessa região suburbana, "pois só se pode esquecer aquilo que em algum momento foi registrado".

6 Vale citar a definição já clássica de Coli (1995, p. 109): "A arte tem assim uma função que poderíamos chamar de conhecimento, de 'aprendizagem'. Seu domínio é o do não racional, do indizível, da sensibilidade: domínio sem fronteiras nítidas, muito diferente do mundo da ciência, da lógica, da teoria. Domínio fecundo, pois nosso contato com a arte nos transforma. Porque o objeto artístico traz em si, habilmente organizados, os meios de despertar em nós, em nossas emoções e razão, reações culturalmente ricas, que aguçam os instrumentos dos quais nos servimos para apreender o mundo que nos rodeia”. 
Para compreender a motivação de José Eduardo para constituir o Acervo da Laje, é preciso acompanhar o modo como ele narra sua própria história. Nesse sentido, há um momento especialmente significativo de sua adolescência:

Com 13 anos descobri que eu era gente. Tem um momento na vida que você se revela a você, sabe? Parece que acontece alguma coisa que você se dá conta: "Opa, eu existo". [...] Até os 13 anos, eu era um dos meninos mais rebeldes do bairro [...]. Mas tinha um casal, Vera e Lázaro, ${ }^{7}$ que tomava conta da comunidade. [...] Vera disse que Lázaro tinha medo do que ia acontecer comigo. Por isso, tudo o que podia fazer para me inserir, ele me inseria. E no ano de 1987 eles pagaram o curso de datilografia para mim, que foi fundamental. Foi quando conheci Drummond, ${ }^{8}$ Clementina de Jesus, ${ }^{9}[\ldots]$. Para mim que vivia naquele... A gente subia numa laje e dizia: "Olha, lá é São Paulo, a gente vai para São Paulo". [...] Depois, a Vera e o Lázaro começaram a viajar e me pediam para tomar conta da casa deles, e pá! A casa deles era cheia de livros e discos. [...] Era uma casa aqui maravilhosa, tinha biblioteca, tinha discoteca, tinha tudo. Ouvi Elis Regina, ${ }^{10}$ Tom Jobim, ${ }^{11}$ Chico, ${ }^{12}$ Caetano, ${ }^{13}$ tudo nessa casa. Descobri que existia pintura, arquitetura, igreja, tudo nessa casa. Ficava folheando livros, depois saía pela cidade para ver. Até os 13 não tinha saído daqui do bairro. E comecei a ir, sozinho. Lembro que conheci todas as igrejas de Salvador, as antigas, e ficava chorando.

Para José Eduardo, a percepção de si mesmo como existente no mundo aconteceu em um período bem preciso de sua vida: com 13 anos descobri que era gente. A surpresa e o maravilhamento vividos naquele ano de 1987 são um divisor de águas em sua trajetória. Antes dos 13 anos, sinaliza que se movia em caminhos muito próximos às fronteiras da marginalização. Após o ponto de virada, sua narrativa apresenta outra face, que apreendemos ainda hoje ser constitutiva do seu

7 Vera Lazzaroto e Antonio Lázaro. Em 1978 o casal mudou-se para Salvador, dedicando-se desde então a diminuir a pobreza e fomentar a educação na região de Novos Alagados.

8 Carlos Drummond de Andrade (1902-1987). Poeta e escritor brasileiro, cuja obra poética é considerada a mais influente do século XX no país.

9 Clementina de Jesus da Silva (1901-1987). Cantora de samba, conhecida por seu inconfundível timbre de voz. Empregada doméstica por mais de vinte anos, em 1963, foi lançada no meio musical por Hermínio Bello, alcançando grande sucesso.

10 Elis Regina Carvalho Costa (1945-1982). Uma das maiores intérpretes da Música Popular Brasileira (MPB).

11 Antônio Carlos Brasileiro de Almeida Jobim (1927-1994). Considerado um dos maiores expoentes da MPB, foi um dos criadores da Bossa Nova. Músico polivalente, foi cantor, compositor, pianista, maestro, violonista e arranjador.

12 Francisco Buarque de Hollanda (1944-). Considerado um dos maiores músicos da $\mathrm{MPB}$, é também escritor e dramaturgo.

13 Caetano Emanuel Vianna Telles Velloso (1942-). Músico e escritor baiano, além de grande expoente na MPB, é conhecido como fundador do Tropicalismo, movimento musical inovador surgido em fins da década de 1960. 
modo de se colocar no mundo: alguém permanentemente fascinado - pela beleza, particularmente - que sem ressalvas corre atrás do que reconhece como valor.

Abrindo a ele sua casa, na verdade, o que o casal Vera e Lázaro lhe ofereceu foi a oportunidade de enxergar o esplendor da própria humanidade. Relacionando-se com Vera e Lázaro de modo muito concreto - oferecendo o curso de datilografia, chamando-o para tomar conta da casa -, José Eduardo entende que eles buscavam cuidar da sua formação por meio da inserção cultural. Ações simples que, no entanto, tiveram uma reverberação estrondosa em sua vida: naqueles livros e discos ele se embriagou do mundo.

Quando o adolescente - que de cima da laje apontava para o horizonte dizendo "lá é São Paulo" e até então nunca tinha saído do bairro - foi acolhido por alguém que se preocupava com seu destino e lhe ofereceu o acesso a grandes gênios da literatura e da música, entendemos que não foi apenas um pouco de erudição que enriqueceu seu repertório: foi própria a dimensão ontológica que se descortinou a ele. Ancorados nas compreensões que José Eduardo articula ao nos apresentar o sentido do trabalho que hoje realiza, entendemos que - ainda que pré-reflexivamente - já naquele primeiro encontro com a produção humana enquanto excedente, seu próprio ser se revelou como feito para o excedente e digno do excedente. E no mesmo ato também se manifestou a ele a essência do humano como ser capaz de produzir o excedente porque ontologicamente aberto ao excedente.

Saber dessa abertura como constitutiva significa se perceber como já sendo humano: descobriu que era gente; não que poderia chegar a ser. Entendemos que a potência transformadora está justamente aí, no reconhecimento de que a humanidade enquanto abertura ao excedente é um dado. Um dado que, com dor, José Eduardo reconhece poder não ser atualizado na experiência, pois sabe que existem pessoas no Brasil hoje que não internalizaram o que o humano elaborou, pessoas que são privadas de tudo. Não obstante, a abertura permanece sendo potência constitutiva, tanto que mesmo nos espaços onde não têm acesso, quando as pessoas encontram, sabem que foram feitas para aquilo. E podem, como ele, se darem conta da vida mesma como existência.

Para José Eduardo, essa modalidade de experiência se deu em um acontecimento vivido como ruptura. No encontro com expressões artísticas, ele viu a beleza produzida pela mão bumana e reconheceu seu rosto refletido nela. Mais uma vez recorremos à metáfora do espelho: uma alteridade que lhe permitiu vislumbrar o próprio ser e se descobrir maior que as determinações de sua história ou limitações de seu contexto. Ele se deu conta de que sua pertença à humanidade o insere em um horizonte imenso e, portanto, se o humano é capaz de algo grande, também ele pode se mover em busca dessa grandiosidade que o realiza.

Quando eu entrei na faculdade de pedagogia, fazia no Recôncavo o mesmo que fiz com as igrejas. Pegava os inventários sobre a Bahia do Instituto do Patrimônio Artístico e Cultural, e ia. E descobria coisas maravilhosas assim.

Já no mestrado e no doutorado, estudei violência entre jovens no subúrbio durante quinze, dezesseis anos. $\mathrm{Na}$ defesa da tese, em 2008, um professor, 
Gey Espinheira, me pediu para ver o outro lado desse subúrbio, ver a beleza. [...] Eu achava que não tinha beleza, não tinha essa elaboração. Porque estudei violência do meu lugar e quando você vê a beleza, ela existe, está ali.

No final de 2009 comecei a entrevistar pessoas e a mapear [os artistas da região]. Quando Marco chegou, eu já estava com uma pequena rede de pessoas para entrevistar. [...] Começamos a procurar onde é que tinha artista aqui e o que era produzido, que nem as pessoas daqui conheciam. [...] No fim da pesquisa, me dei conta de que cada artista pesquisado tinha que ter uma obra. [...] Em 2011, as pessoas começaram a vir ver isso aqui. Comecei a me dar conta de que estava acontecendo alguma coisa diferente. Veio uma jornalista fazer uma reportagem porque eu estava lançando um livro na Itália. No meio da conversa falei para ela: "Olha, isso aqui está se tornando um acervo".

Além de ressoar afetivamente e mobilizar elaborações, o maravilhamento ante o dado da existência pede por algo além da fruição de um fascínio, pede por uma resposta que afirme a maravilha no cotidiano da vida. Foi isso que entendemos que José Eduardo fez intuitivamente em suas visitas a igrejas da cidade e viagens durante a graduação. É isto que ele radicalizou como projeto de vida na pesquisa com artistas e na constituição do Acervo. E é isto que ele espera - e se empenha para - ver acontecer em quem visita e participa das atividades educativas do Acervo: que a experiência correspondente da beleza fomente a descoberta da potência da humanidade e da própria humanidade, que se torne critério e mobilize tomadas de posição. E, enquanto propõe a todos - e especialmente aos jovens -, essa modalidade de experiência que vivenciou não deixa de se surpreender: por causa disso daqui muita gente começou a se pertencer.

E o seu modo de propor é priorizar o autoral em detrimento da visão estereotipada que a mídia insiste em propor ao retratar a periferia nas telenovelas:

Por isso tenho muito medo de trazer coisas estilizadas para cá. O que me interessa tem a estética própria. [...] Na nossa configuração cultural, estamos esquecendo a questão autoral. Mas, na história da humanidade, visitar um museu e ver o quadro original é fundamental para você se dar conta daquele instante, que por ser instante se torna eterno e permanece ad infinito. [...] Quando você vê a obra original, tem um encontro que se estabelece que é a condensação de uma vida num instante. $\mathrm{E}$ aquilo fica, é um patrimônio. Quando você vê o original, isso te faz ao mesmo tempo pertencer, se reconhecer diante daquele quadro ou não.

Assim, mesmo que os tempos tenham mudado e hoje ninguém abra a casa para deixar criança, adolescente entrar para ver, como Vera e Lázaro faziam, é justamente isso que ele faz por meio do Acervo. Ofertando arte como testemunho do ímpeto humano, José Eduardo em um só ato cuida das novas gerações e se reconecta às origens de sua formação. Entendemos que por isso é importante que as obras no Acervo da laje sejam autorais e não estilizadas: porque elas precisam reenviar à fonte, precisam permitir que os jovens se descubram gente - como ele um dia 
se descobriu - diante da expressão do ímpeto humano de avançar sempre além de quaisquer enquadramentos. Como recriação da experiência originária na casa de Vera e Lázaro, o Acervo tem a originalidade de avizinhar ainda mais a beleza, pois ali os artefatos que materializam a riqueza cultural do suburbio encontram-se disponíveis ao toque da mão.

Uma de suas preocupações é evitar cair na massificação que homogeneiza tudo ao reconhecer que, naquilo que nos une, há espaço também para o que nos singulariza. Apreendemos esse dinamismo no cuidado que ele demonstra em valorizar os elementos do Candomblé e desmistificar preconceitos, pois, embora não seja adepto dessa religião, ela diz muito da pertença das pessoas em Salvador. Do mesmo modo, identificamos em várias de suas assertivas essa abertura à unidade entre universal e particular: todos temos uma pertença, a cada um cabe pertencer ao povo de um território. Todos os artistas querem superar o normal, cada um deixando a sua marca. Todas as periferias têm beleza, cada qual a seu modo: isso aqui você não encontra em nenhuma periferia do Brasil, mas, na periferia que você for, vai encontrar referências dela.

Tão intenso e constante quanto seu encantamento com a beleza e com o excedente é seu assombro diante da não atualização dessa abertura constitutiva do humano: essa coisa que está mais lhe chocando, existem pessoas que são privadas de tudo. A existência pode ser impedida de encontrar um significado do humano elaborado ou, mesmo encontrando, pode não se deixar transformar por sua radicalidade. Sobre essa última possibilidade, José Eduardo nos narrou sua perplexidade ante os universitários que se deixam levar pela banalidade e sua tristeza no encontro com um grupo de artistas que, mesmo tendo um talento genial e financiamento, viviam daquela forma, drogando-se desde o momento em que acordavam.

Dar-se conta de que a fatalidade do achatamento da humanidade não apenas pode acontecer, como cotidianamente acontece, o indigna e mobiliza. E percebemos que para o idealizador do Acervo da Laje é importante tematizar as negações daquilo que ele se dedica a afirmar:

Essa é a luta da memória e do esquecimento: de uma hora para a outra a memória foi suplantada. Coisas que são fundamentais para conhecer e ter uma dimensão de pertença ao lugar foram destruídas: sambaquis, ${ }^{14}$ igrejas antigas... No lugar que tem uma igreja de quatrocentos anos pessoas são assassinadas. É isso: quando vem a violência, apaga tudo. [...] Nesses espaços os vínculos não vão se manter, não vai ter pertença. Então precisa de um lugar físico, algo para fazer a pertença acontecer.

14 Sambaqui, do tupi tamba'kï: "monte de conchas". Comuns em todo litoral atlântico, os sambaquis têm aspecto de colinas e são jazidas formadas pela acumulação de restos de conchas, elementos culturais e sepultamentos humanos. José Eduardo refere-se ao Sambaqui de Pedra Oca, em Periperi, que teria sido produzido há cerca de mil e quinhentos anos, segundo estudos arqueológicos ali desenvolvidos por Calderón (1964). 
Em tantos momentos, sua elaboração aproxima os opostos: a denúncia do limite às assertivas quanto ao potencial; a dor pela fragilidade à admiração diante da força; a incerteza sobre a continuidade à descrição das ações de preservação em curso. Em sua experiência, a defesa do valor se faz entranhada da consciência do drama de que esse mesmo valor pode não se concretizar. Nesse sentido, com a narrativa de José Eduardo apreendemos que a ferida acesa da negação da humanidade alimenta o motor do cuidado daquilo que ele reconhece como valor, o que não elimina o fato de que tais negações continuem a machucar.

Como a arte pode incidir na trajetória de desenvolvimento de pessoas em situações adversas? É muito difícil prever o desenvolvimento, pensar que algo pode modificar a sua vida a partir de uma experiência de encontro com uma variedade de símbolo, de arte. Mas eu vim da pesquisa de trajetórias de marginalidade, em que também tem um momento em que acontece esse encontro. Ninguém nasce para ser marginal, há algumas coisas que acontecem na trajetória do indivíduo que levam para determinadas escolhas: a fragilidade dos vínculos na família, a inserção de pares que também são marginais, as primeiras inserções na droga. [...] Tem meninos aqui que nunca saíram do beco da rua onde moram, que nunca foram no centro da cidade, no cinema, no museu, teatro, nada. Têm uma restrição cultural. [...] Além disso, para mim uma das grandes causas da violência é a falta de enraizamento e de pertença. É os meninos não se reconhecerem uns nos outros. Eles olham para os outros e não se vêem, eles podem matar facilmente. [...] Mas, em vários casos no mundo, em situações parecidas de marginalização, meninos encontraram um elemento cultural que de repente alavancou dentro deles uma outra perspectiva.

Vindo de pesquisa de trajetórias de marginalidade, José Eduardo nos descreve com precisão a lógica perversa que se instaura em contextos de vulnerabilidade, da qual o tráfico se alimenta. Trata-se de uma diminuição da humanidade que não é necessária na pobreza, mas que acontece quando há ruptura de vínculos e estabelecimento de relações pragmáticas, em que as pessoas não se reconhecem umas nas outras e assim tomam a violência como o único caminho possível. A negação do enraizamento como direito resulta, para ele, no estreitamento da visão de si e de mundo e na inabilidade em preservar qualquer tipo de coisa: trata-se de uma lógica necessariamente contrária a qualquer tipo de constituição comunitária. Entretanto, a experiência lhe mostra que quando encontram um elemento cultural provocador, essas mesmas pessoas percebem que a própria estrutura é exigência de mais e podem então ter critério.

Acompanhando a elaboração de José Eduardo, percebemos que esse não é um discurso abstrato, mas um ideal totalmente encarnado: essa é a sua contribuição ao drama histórico de seu subúrbio e mais especificadamente de sua comunidade, Novos Alagados. Para ele, o direito à memória implica que a referência ao que veio antes - e quem veio antes - possa permanecer, sendo cotidianamente atualizada e reconfigurada. Daí a importância de restituir quando se sabe onde estão as obras; denunciar o abandono enquanto os monumentos antigos ainda não foram totalmente destruídos; registrar a vida e a lembrança das pessoas antes que elas partam. 
Assumindo essa luta da memória e do esquecimento, José Eduardo faz questão de se diferenciar dos movimentos de resgate que buscam o fortalecimento comunitário por meio de tentativas de retorno a uma identidade pretérita, muitas vezes sem se preocuparem em trabalhar com elementos verídicos. Para ele, não basta um exercício aproximativo ou especulativo, já que resgate exige uma base documental, que foi muito perdida em relação à Babia. [...] Jáa a restituiçẫo, para mim, é mais possivel, no sentido de que, com os dados que tenho, eu sei onde encontrar as obras que fazem parte do patrimônio cultural civilizatório dessa região. Por isso, José Eduardo enfatiza sua capacidade de descobrir e adquirir as obras dos artistas do subúrbio sem tentar forçar uma reconstrução histórica artificial.

Entendemos que ao diferenciar restituição e resgate, ele quer nos mostrar que não é necessário maquiar raízes: o acesso à beleza existente no subúrbio é potente o bastante para colocar você numa perspectiva da vida, do presente, do passado, do futuro, e você se sente humano. É potente o bastante para fomentar a constituição de um futuro enraizado e um cuidado real com o que vem do passado. Dando as mãos aos mestres que defenderam a força que continua pulsando na periferia a despeito de toda deterioração, José Eduardo se apresenta como continuador desse árduo trabalho de cultivo do valor reconhecido em sua terra natal.

Acho que estudar, para mim, foi muito isso: cuidar dessa coisa da memória. [...] É uma luta e para mim, assim, eu não queria, mas eu aceitei. Eu não queria, mas eu aceitei, e tem um risco. Você tem que ter uma disponibilidade intencional: se me chamam para fazer uma entrevista, eu não gosto, tenho pavor, mas eu vou. [...]

Eu segui um caminho que foi totalmente autoral, não sei onde é que isso vai dar. E isso dá medo? Dá medo. [...] Sei que posso não passar em concurso nenhum. [...] Mas é muito bom poder estar fazendo, do meu jeito, do jeito que é possível. Não é o melhor, não é o mais ordenado, mas é o meu jeito, é o jeito que foi dado de fazer.

Consciente da peculiaridade do seu caminho, o criador do Acervo da Laje salienta sua coragem em aceitar os riscos da luta que é testemunhar e celebrar a expressão propriamente humana existente nos contextos caracterizados pelo pragmatismo, provando para o mundo que pobreza não é correlato de privação cultural. Luta que ele não escolheu e afirma mesmo que não queria, mas assumiu com disponibilidade intencional. Sua decisão é doar-se de um jeito que sabe não ser o melhor, ou o mais ordenado, mas é o seu. É o modo como entende dar uma contribuição efetiva para a constituição da comunidade.

E assim, escancarando a potência do excedente com o desejo aceso de superar o paradoxo de sua invisibilidade, José Eduardo descobre que está cuidando de si: todo esse trabalho elaborou alguma coisa, restaurou alguma coisa em si mesmo. Memória é uma coisa que a gente cuida dos outros, mas a gente está cuidando da gente, sabe? A dedicação à sua comunidade coincide com a dedicação consigo: a percepção do próprio ser é de um ser feito de relações e de raízes fincadas naquele mangue. 


\section{AMPLIANDO COMPREENSÕES NO DIÁLOGO COM SIMONE WEIL}

Simone Weil (2001) é a autora com quem convidamos a experiência de José Eduardo a dialogar. Escolha sintonizada com o fato de ele mesmo ter se debruçado sobre a contribuição teórica dessa filósofa (Santos, 2014) e durante a entrevista ter mencionado de seus conceitos fundamentais: o enraizamento. Apreendemos nessa referência uma boa chave de leitura para ampliar as compreensões alcançadas sobre a experiência educativa do Acervo da Laje.

Para tanto, acompanhemos Weil (2001, p. 43) em sua definição que já se tornou clássica:

O enraizamento é talvez a necessidade mais importante e mais desconhecida da alma humana. É uma das mais difíceis de definir. Um ser humano tem raiz por sua participação real, ativa e natural na existência de uma coletividade que conserva vivos certos tesouros do passado e certos pressentimentos do futuro. Participação natural, ou seja, ocasionada automaticamente pelo lugar, nascimento, profissão, meio. Cada ser humano precisa ter múltiplas raízes. Precisa receber a quase totalidade de sua vida moral, intelectual, espiritual, por intermédio dos meios dos quais faz parte naturalmente.

Identificando no enraizamento um processo fundamental de constituição do ser humano, Weil assevera que é realmente fazendo parte de um mundo coletivo natural que a pessoa pode florescer em seu aspecto mais próprio e também mais humano. Não significa que não se possam receber influências externas à própria comunidade: o ponto é que a pessoa elabore tudo o que recebe com base em suas próprias raízes.

Em primeiro lugar é evidente a ligação entre pertencer e se pertencer: para a filósofa, é necessidade da alma participar de uma coletividade, pois é de suas raízes que o ser humano retira a seiva que o sustenta na totalidade da vida. Com José Eduardo, vimos a possibilidade de que a experiência revele essa ligação como ainda mais radical: descobrindo a si mesma como humana, a pessoa reconecta-se às raízes; descobrindo as próprias raízes, reconecta-se à própria humanidade. Tomando a liberdade - pretensiosa? - de propor uma revisão ao modo de descrever essa necessidade humana, o que aprendemos com a análise da experiência é que, mais que "precisar ter múltiplas raízes", trata-se de reconhecer o que já se tem. Exaltar a existência - ainda que abalada ou deteriorada - do vínculo com a própria coletividade é descobrir que não precisamos buscar uma solução da continuidade entre ser si mesmo e ser com: a abertura ao acolhimento do existente revela essa unidade como evidência - que pode sim ser abafada, mas jamais extirpada.

Avançando no diálogo, a filósofa descreve o desenraizamento como processo que acontece não porque as pessoas se encontram longe geograficamente de seus lares, mas porque vivem como estrangeiros em si mesmos, alheios à própria formação natural, exilados de sua origem sociocultural, "moralmente desenraizados" (Weil, 2001, p. 45). Como consequência desse exílio, dois são os comportamentos possíveis: ou o sujeito (individual ou coletivo) se submete a imposições externas, 
reproduzindo o discurso dominador e criando idolatrias, ou se lança em atividades desenraizadoras, frequentemente por meio de métodos violentos. O ponto é que, de um lado ou de outro, o sujeito encontra-se alienado de si, pois lhe falta uma base que o sustente nos momentos de crise: "uma árvore cujas raízes estão quase inteiramente corroídas cai ao primeiro choque"(Weil, 2001, p. 45).

Nessa definição do desenraizamento, identificamos outra sintonia fundamental com a análise da experiência que empreendemos. Buscando uma imagem que a expresse, vislumbramos que, quando nasceu erguendo suas palafitas sobre a maré, a comunidade de Novos Alagados necessitou buscar troncos fortes que a fincassem naquele solo encharcado de mar. Do mesmo modo, o desafio presente é que suas raízes se fortaleçam e resistam às intempéries da maré de desagregação que a assola. Nessas condições, a proposta educativa empreendida por José Eduardo nos ensina que de nada adianta um pilar externo, fincado em outro território: cada um precisa se dar conta em primeira pessoa de que necessita daqueles sustentáculos que são os seus, frágeis sim, mas seus - e aqui identificamos o aspecto "natural" e os riscos da alienação de que fala Weil.

Para ela, o desenraizamento é uma doença que pode atingir todas as classes sociais, etnias e povos. Doença perigosa não só pelo mal que causa àqueles que estão contaminados, mas também porque rapidamente se dissemina. "Quem é desenraizado, desenraiza" (Weil, 2001, p. 47), constata diante da evidência de que a sociedade moderna, desenraizada, propõe uma cultura de massa vulgarizada e uma educação puramente técnica, pragmática, especializada e fragmentada.

José Eduardo, de modo similar, defende que não se pode assentir à visão estereotipada de que o subúrbio é só violência: voltando à nossa metáfora, não se pode aceitar a oferta de um toco já corroído como pilastra da própria casa. É fato que a violência corrói a comunidade disseminando a lógica do pragmatismo que abala os vínculos e a possibilidade de apoio mútuo. No entanto, o excedente continua a se reapresentar como existente e urge abrir os olhos e ativamente buscá-lo, reconhecendo que este é e precisa ser o verdadeiro fundamento da percepção pessoal e coletiva e também da educação de seu povo. Isso traz o desafio de como lidar com aqueles que encarnam a alteridade à comunidade: nessa luta por visibilidade e inclusão social, como estruturar relações em que a periferia seja reconhecida e afirmada por ela mesma e pela sociedade em geral, mas sem se subjugar ao olhar do outro? Esta é uma questão tensa e dramática em sua experiência, ainda em aberto.

Ainda sobre o drama do desenraizamento, Weil (2001) identifica que diante dele há duas possibilidades: ou essa doença contamina a todos, ou transformamos a sociedade de modo tal que as pessoas possam ter raízes. Nessa segunda alternativa, destaca a importância do esforço educativo que retoma o que nos foi passado para que possamos abrir novas perspectivas futuras enraizadas. Não se trata de tentar que o passado destruído retorne, mas sim de possuir os tesouros herdados do passado digerindo-os, assimilando-os, recriando-os pelo nosso posicionamento presente. Cabe a nós, enquanto sujeitos partícipes de uma coletividade, nutrirmo-nos dessa seiva para construir o futuro dando-lhe a vida. Tomado nesses termos, o enraizamento sustenta e é sustentado por uma experiência de nós, que pode ser potencializada pela iniciativa de alguns. Como Mahfoud (2012), parafraseamos 
Weil: quem é enraizado, enraíza, isto é, promove formação humana, gera protagonismo, fecunda relacionamentos construtivos.

É exatamente isso que apreendemos ao acompanhar as elaborações de José Eduardo. Vimos que ele nasceu em um território em que a potência do mangue encontrava-se corrompida pelos dejetos da cidade e da humanidade, tal como a força da cultura de afirmação do humano encontrava-se - e ainda se encontra - ameaçada pelo avanço de propostas outras, como o pragmatismo que arranca as pessoas de si mesmas e do seu lugar no mundo, encarcerando-as na própria reatividade. Ele próprio nos anunciou que transitava nessa fronteira e, acompanhado por alguém preocupado com seu destino, teve a possibilidade de se formar embebendo-se da cultura que expressa o excedente humano, para mais tarde acolher a missão de identificar, nutrir-se e nutrir seu povo com esse excedente que teimosamente não cessa de escorrer ali mesmo.

E, assim como o seu mangue, que hoje mostra com a volta das conchas os sinais de sua recuperação, a análise nos indica que, fortalecido em suas raízes, José Eduardo se apresenta como protagonista que contribui para vivificar o solo apodrecido de sua comunidade, fertilizando-a com seu próprio substrato: uma proposta educativa que afirma a potência complexa do humano. Uma educação que, estando viva como o mangue, pode oxigenar a experiência, cabendo às raízes pessoais o trabalho de acolher os nutrientes que lhe são oferecidos transformando-os na seiva que a cada um em particular e a comunidade como um todo precisam hoje, com as exigências do presente.

Por fim, destacamos a assertiva de Weil de que a educação pela via da promoção cultural tem um papel fundamental no processo de (re)enraizamento: para a filósofa, enquanto a modernidade vulgariza a cultura ou a torna "coisa de especialistas"(Weil, 2001, p. 65), é preciso traduzi-la para comunicar a verdade nela contida de modo adequado à realidade de quem a está recebendo.

Não tomar as verdades, já excessivamente pobres, contidas na cultura dos intelectuais, para as degradar, mutilar, esvaziar o seu sabor; mas simplesmente expressá-las, em sua plenitude, por meio de uma linguagem que, segundo a expressão de Pascal, as torne sensíveis ao coração. (Weil, 2001, p. 65)

Não se trata de processo fácil, uma vez que somente quem apreendeu o que há de essencial em uma expressão cultural específica tem condições de traduzi-las por meio de outras manifestações. "É preciso ter-se colocado no centro de uma verdade, tê-la possuído em sua nudez, por trás da forma particular sob a qual ela se encontra por acaso exposta" (Weil, 2001, p. 65). Assim como a expressão cultural original, esse processo de tradução também é uma arte, fruto de um posicionamento humano atento à verdade ali comunicada. Para Weil, é possível que essa experiência circunscrita abra caminho para a criação de um espaço cultural no qual as pessoas se sintam em casa, à vontade, de modo que aquele espaço seja ocasião para expressões e elaborações culturais que alimentem a alma, que promovam o enraizamento. 
Identificamos com José Eduardo, no caso da sua comunidade, a urgência de que esse espaço cultural tenha um endereço bem definido. Contra tantas correntes de um mar bravio e por estarem ancoradas em um terreno que historicamente se tornou vulnerável, as raízes fragilizadas do subúrbio precisam tecer uma estabilidade excepcional. Daí a importância nas atividades de educação não formal por ele propostas de que, além da materialidade de um espaço físico, seja possível à população local o acesso à materialidade de obras que visibilizem o excedente, que o façam palpável, presença incontestável no cotidiano da vida. Onde a transmissão oral parece estar ameaçada pela morte dos pioneiros, o contato com o original se nos apresenta como resposta potente para que a educação atualize sua missão de "re-apresentação" da potencialidade ontológica do ser humano.

\section{CONCLUSÃO}

$\mathrm{Na}$ análise realizada, vimos que o modo como José Eduardo elabora suas experiências sedimenta-se na surpresa diante da existência e na afirmação de sua potência. Cuidando para que a beleza retorne ao solo em que foi gerada e tenha um espaço para ser contemplada, ele dá a sua resposta pessoal, lançando a provocação de que todas as periferias possam ter um espaço como o Acervo da Laje. Lutando pela memória para que sua comunidade se fortaleça, acalenta a esperança de que os jovens transbordem os confins do beco da rua onde moram e, como ele, abracem o desafio de dar uma contribuição que promova o desenvolvimento do contexto. Enquanto espera por essas repercussões, segue se concentrando na potência mobilizadora do reconhecimento no presente: a afirmação da existência é seu modo de propor experiências educativas.

Com a clara consciência da possibilidade de que a potência humana não se realize, seus esforços buscam mirar o ponto essencial: é assim que ele se reconhece cuidado em diferentes momentos de sua história, é isso que já buscava como educador antes de constituir o Acervo da Laje, e continua buscando ao oferecer o que possui de melhor no intuito de mobilizar rupturas na dinâmica do pragmatismo. Sua compreensão é de que, deparando-se com a preciosidade que existe no subúrbio, a pessoa pode reconhecer que, pertencendo a esse lugar, pertence a um horizonte imenso, encontrando aí algo mais correspondente a si que a banalidade da violência que rege o mundo do tráfico. Assim, embora enfrente os riscos de permanecer centrada na pessoa de seu idealizador (Sovik, 2014), vemos como a educação não formal desenvolvida no Acervo da Laje tem a chance de não incorrer no assistencialismo ao buscar favorecer posicionamentos críticos e ativos em seu público-alvo (Matos, 2015).

Concebida como promotora de pertença, a experiência educativa em questão direciona seus esforços para um lugar específico, que é belo e rico culturalmente, mas que, em um preciso momento histórico, passou a ser sinônimo apenas de privação, dispersando-se o contato com a riqueza que subsiste ali. Assim, contra a visão estereotipada de que o subúrbio tem que ser violento — visão que a mídia tantas vezes reproduz -, o Acervo soma esforços para quebrar a invisibilidade. Retomando a denúncia feita por Sovik (2014) de que o empenho por visibilidade empreendido 
pelos projetos culturais pode absorver o espaço dedicado à formação artística como caminho para a educação, asseveremos a importância de que a educação pela arte permaneça como o centro dessa proposta educativa. Nesse sentido, a visibilidade precisa despontar como corolário, possibilidade de mostrar também ao mundo que no subúrbio tem sim a violência, mas existe muito mais: há uma complexidade que iniciativas como essa podem nos ajudar a perceber.

O Acervo da Laje, nascido em um espaço em que moradias eram construídas sobre o mangue, mostra-se a nós com a solidez de casa construída sobre rocha. Embora ainda existam muitos desafios a serem superados - podemos citar a necessidade de sistematização das metodologias pedagógicas utilizadas, já indicada por Gohn $(2007,2009)$ como recorrente em práticas de educação não formal —, entrevemos a força dessa proposta educativa que não pretende acrescentar nada, e sim evidenciar a potência que já existe na periferia. Seria esse enraizamento na existência o segredo da solidez dessa iniciativa que segue crescendo e frutificando sem se pautar pelo acesso ou não a financiamentos? Pulsante contra as intempéries, o Acervo revela-se pujante como o mangue que renasce quando alguém se empenha para que o esgoto não o sufoque.

No diálogo com Simone Weil (2001), continuamos a aprender com essa experiência que testemunha como enraizamento é sinônimo de florescimento, pois, enraizadas, as pessoas podem se reconhecer inteiras e atualizarem a potência do seu ser. Isso não significa que todos os problemas estejam resolvidos ou todas as tensões aplacadas, mas descortina uma possibilidade de vitalidade mesmo em meio a condições adversas.

Entendemos serem esses alguns dos aspectos essenciais da proposta educativa que fundamenta as atividades desenvolvidas no Acervo da Laje. Aprofundando o modo como seu fundador elabora essa experiência, identificamos desafios e provocações que esperamos poderem se constituir como contribuição real para a reflexão sobre como iniciativas similares podem aliar a dupla tarefa da educação - desenvolvimento das novas gerações e renovação de um mundo comum - à almejada transformação social por meio da inserção cultural. No caso em análise, a centralidade do enraizamento revela uma possibilidade cuja singularidade identificamos na valorização concomitante da cultura local e do que nos une como humanos.

\section{REFERÊNCIAS}

Ales Bello, A. Culturas e religióes: uma leitura fenomenológica. Tradução de Antonio Angonese. Bauru: EDUSC, 1998.

. Fenomenologia e ciências humanas: psicologia, história e religião. Tradução de Miguel Mahfoud e Marina Massimi. Bauru: EUSC, 2004.

Arendt, H. Entre o passado e o futuro. 7. ed. Tradução de Mauro W. Barbosa. São Paulo: Perspectiva, 2011.

Augras, M. Alteridade e dominação no Brasil: psicologia e cultura. Rio de Janeiro: Nau, 1995. 
Barreira, C. R. A. Da história da fenomenologia à ética na psicologia: tributo ao centenário de filosofia como ciência rigorosa (1911) de Edmund Husserl. Memorandum, Belo Horizonte: UFMG; Ribeirão Preto:USP,v.20, p. 135-144, abr.2011. Disponível em: <seer.ufmg.br/index.php/memorandum/article/view/9807 >. Acesso em: 19 jan. 2018. Barreira, C. R. A.; Ranieri, L. P. Aplicação de contribuições de Edith Stein à sistematização de pesquisa fenomenológica em psicologia: a entrevista como fonte de acesso às vivências. In: Mahfoud, M.; Massimi, M. (Orgs.). Edith Stein e a psicologia: teoria e pesquisa. Belo Horizonte: Artesã, 2013. p. 449-466.

Bienal de São Paulo, 3 I., 201 4 , São Paulo. Simpósio usos da arte. 9 set. 2014. Disponível em: <www.31bienal.Org.br/pt/post/1328>. Acesso em: 22 jan. 2018.

Bienal da Bahia, 3., 2014, Salvador. Acervo da Laje abriga mais uma seção do Museu Imaginário do Nordeste. Maio 2014. Disponível em: <http://bienaldabahia2014.com.br/ wp/wp-content/uploads/2014/02/Acervo-da-Laje-vale-abriga-seção-do-MIN-.pdf>. Acesso em: 22 jan. 2018.

Bosı, E. Memória e sociedade: lembranças de velhos. 17. ed. São Paulo: Companhia das Letras, 2012.

Calderón, V. V. O sambaqui da Pedra Oca: relatório de uma pesquisa. Salvador: UFBA, 1964.

Coli, J. O que é arte. São Paulo: Brasiliense, 1995.

Espinheira, G. O Parque São Bartolomeu: esquecimento e memória. In: Formigli, A. L. (Org.). Parque Metropolitano de Pirajá: história, natureza e cultura. Salvador: Centro de Educação Ambiental São Bartolomeu, 1998. p. 23-27.

Ferraro, A. R.; Ross, S. D. Diagnóstico da escolarização no Brasil na perspectiva da exclusão escolar. Revista Brasileira de Educação, Rio de Janeiro: ANPed, v. 22, n. 71, p. 1-26, 2017. Disponível em: <http://www.scielo.br/scielo.php?script=sci_ arttext\&pid=S1413-24782017000400217\&lng=pt\&nrm=iso >. Acesso em: 19 jan. 2018. http://dx.doi.org/10.1590/s1413-24782017227164

Gohn, M. G. Não fronteiras: universos da educação não formal. São Paulo: Itaú Cultural, 2007.

.Educação não formal e o papel do educador(a) social. Revista Meta:Avaliação, Rio de Janeiro: CESGRANRIO, v. 1, n. 1, p. 28-43, jun. 2009. Disponível em: <http:// revistas. cesgranrio.org.br/index.php/metaavaliacao/article/view/1>. Acesso em: $15 \mathrm{jan}$. 2018. http://dx.doi.org/10.22347/2175-2753v1i1.1

Husserl, E. Ideias para uma fenomenologia pura e para uma filosofia fenomenológica. Tradução de M. Suzuki. Aparecida: Ideias e Letras, 2006.

LeIte, R. V. Experiência ontológica e tradição na experiência de guardiöes de memórias. Belo Horizonte. 2015. Tese (Doutorado em Psicologia) — Universidade Federal de Minas Gerais, Belo Horizonte, 2015.

Leite, R. V.; Mahfoud, M. Contribuciones de la fenomenología a la investigación sobre la cultura popular y la educación. Krinein, Santa Fe: UCSF, n. 7, p. 127-150, 2010. Mahfoud, M. Folia de Reis, festa raiz: psicologia e experiência religiosa na Estação Ecológica Juréia-Itatins. São Paulo: Companhia Ilimitada, 2003. 
Experiência elementar em psicologia: aprendendo a reconhecer. Brasília, DF: Universa, 2012.

Matos, D. A. Narrativas em tensão: modos de ser jovem na/da periferia. Contemporanea Salvador: UFBA, v. 13, p. 453-470, 2015. Disponível em: <https://portalseer.ufba.br/ index.php/contemporaneaposcom/article/view/12261/9888>. Acesso em: 19 jan. 2018. http://dx.doi.org/10.9771/1809-9386contemporanea.v13i2.12261

Nordeste Mais [Programa de TV]. Direção: Vânia Lima. Salvador: TêmDendê, 16 set. 2017.

Peres, S. P. Husserl e o projeto de psicologia descritiva e analítica em Dilthey. Memorandum, Belo Horizonte: UFMG, v. 27, p. 12-28, out. 2014. Disponível em: <seer.ufmg.br/index.php/memorandum/article/view/6368>. Acesso em: 19 jan. 2018.

Ramos, F. C. Socialização e cultura escolar no Brasil. Revista Brasileira de Educação, Rio de Janeiro, ANPed, v. 23, p. 1-21, 2018. Disponível em: <http://www.scielo.br/ pdf/rbedu/v23/1809-449X-rbedu-23-e230006.pdf>. Acesso em: 19 jan. 2018. http:// dx.doi.org/10.1590/s1413-24782018230006

Santos, J. E. F. Como transformar sua casa em uma obra de arte? Palestra proferida no TEDx (Rio Vermelho), fev. 2017. YouTube. Disponível em: <https://www.youtube. com/watch?v=nTDuumPcaRo . Acesso em: 23 jan. 2018.

SAntos, J. E. F. Novos Alagados: histórias do povo e do lugar. Bauru: EDUSC, 2005.

Acervo da Laje: memória estética e artística do subúrbio ferroviário de Salvador, Bahia. São Paulo: Scortecci, 2014.

Severo,J.L. R. L. Educação não escolar como campo de práticas pedagógicas. Revista Brasileira de Estudos Pedagógicos, Brasília, DF: INEP, v. 96, n. 244, p. 561-576, dez. 2015. Disponível em: <http://www.scielo.br/scielo.php?script=sci_arttext\&pid=S217666812015000300561\&lng= en\&nrm=iso >. Acesso em: 15 jan. 2018. http://dx.doi. org/10.1590/S2176-6681/345513545

Souza, A. M. M.; Ciampa, A. C. "Devemos continuar?” identidade, história e utopia do educador de rua. Psicologia E Sociedade, Belo Horizonte: PUC Minas, v. 29, p. 1-11, 2017. Disponível em <http://www.scielo.br/scielo.php?script=sci_arttext\&pid=S010271822017000100409\&lng=pt\&tlng=pt $>$. Acesso em: 25 jan. 2018. http://dx.doi. org/10.1590/1807-0310/2017v29171957

Sovıк, L. Os projetos culturais e seu significado social. Galaxia (São Paulo), São Paulo: PUC São Paulo, n. 27, p. 172-182, jun. 2014. Disponível em: < http://www.scielo.br/ pdf/gal/v14n27/14.pdf>. Acesso em: 15 jan. 2018. http://dx.doi.org/10.1590/198225542014110411

Van Der Leeuw, G. Fenomenología de la religión. Tradução de E. de la Peña. México: Fondo de Cultura Económica, 1964.

Villaça, I. C. Arte-educação: a arte como metodologia educativa. Cairu em Revista, Salvador: FVC, ano 3, n. 4, p. 74-85, jul./ago. 2014. Disponível em: <http://www.cairu. br/revista/arquivos/artigos/2014_2/05_ARTE_EDUCACAO_METODOLOGIA_ EDUCATIVA.pdf $>$. Acesso em: 18 jan. 2018. 
Von Simson, O. R. M.; Park, M. B.; Fernandes, R. S. Educação não formal: um conceito em movimento. In: Rumos Educação, Cultura e Arte (Org.). Visões singulares, conversas plurais. São Paulo: Itaú Cultural, 2007. p. 13-41.

WeIL, S. O enraizamento. Tradução de M. L. Loureiro. Bauru: EDUSC, 2001.

Zilles, U. Fenomenologia e teoria do conhecimento em Husserl. Revista da Abordagem Gestáltica, Goiânia: ITGT, v. 13, n. 2, p. 216-221,2007. Disponível em: <pepsic.bvsalud. org/scielo.php?pid=S1809-68672007000200005\&script=sci_arttext >. Acesso em: 15 jan. 2018.

\section{SOBRE OS AUTORES}

Roberta Vasconcelos Leite é doutora em psicologia pela Universidade Federal de Minas Gerais (UFMG). Professora da Universidade Federal dos Vales do Jequitinhonha e Mucuri (UFVJM).

E-mail: vasconcelosroberta@yahoo.com.br

Miguel Mahfoud é doutor em psicologia social pela Universidade de São Paulo (USP). Professor da Universidade Federal de Minas Gerais (UFMG). E-mail:mmahfoud@yahoo.com

Recebido em 29 de janeiro de 2018 Aprovado em 4 de junho de 2018 